\title{
PARIDAD DE GÉNERO EN MÉXICO: ¿Infracción al principio democrático de igualdad?
}

\author{
Joaquín ORDÓÑEZ \\ Universidad Autónoma del Estado de México \\ joaquin.o@me.com
}

GENDER PARITY IN MEXICO: Violation of the democratic principle of equality?

Resumen: En México ha ido evolucionando el tema de la participación femenina en los procesos electorales desde la regulación de las cuotas hasta llegar al establecimiento constitucional y legal de la paridad de género como un deber para los actores electorales. La causa que lo ha motivado se apoya principalmente en razones de tipo político y social y dista mucho de tener una justificación que lo relacione con la esencia del principio democrático de igualdad. Por ello, en este trabajo sostengo que, independientemente de que cumpla con su objetivo político, social o electoral de distribuir de forma igual las candidaturas y los cargos públicos, la paridad contrasta e incluso contradice conceptualmente a la igualdad democrática.

Abstract: In Mexico, the issue of female participation in electoral processes has evolved from the regulation of quotas to the constitutional and legal establishment of gender parity as a duty for electoral actors. The cause that motivated it is based mainly on political and social reasons and is far from having a justification that relates it to the essence of the democratic principle of equality. Therefore, in this paper I argue that, regardless of whether it fulfills its political, social or electoral objective of equally distributing candidacies and public offices, parity contrasts and even contradicts conceptually democratic equality.

Palabras clave: Paridad De Género. Democracia. Igualdad Democrática. Libertad Democrática Gender Parity. Democracy. Democratic Equality. Democratic Freedom 


\section{Introducción}

En México se tiene toda una cronología de sucesos relacionados con la participación de la mujer en las elecciones estatales, ${ }^{1}$ lo que ha llevado a la inclusión de instrumentos afirmativos que han ido desde las cuotas de género ${ }^{2}$ hasta la paridad. ${ }^{3}$ Asimismo, diversos instrumentos nacionales ${ }^{4}$ e internacionales ${ }^{5}$ han continuado en el perfeccionamiento de esta política de género para que la participación femenina en asuntos de Estado sea ejercida con una mayor frecuencia. En términos generales, las cuotas de género para la participación electoral se conforman con la finalidad de que haya justicia social, es decir, se trata de un

1 Como ejemplo se puede mencionar el histórico suceso a principios del siglo XX, en el que ciertos movimientos feministas contradijeron a la legislación que no reconocía el derecho de las mujeres a ocupar cargos de elección popular, tal fue la postulación de Hermila Galindo (para diputada federal por la Ciudad de México en 1928), Elvia Carrillo Puerto (para diputada federal por San Luis Potosí en 1926) y Refugio García (para diputada federal por Michoacán en 1937) (Cano, 2001:753); posteriormente, el 24 de diciembre de 1937, el presidente Lázaro Cárdenas del Río envió una iniciativa de reforma al artículo 34 constitucional que permitiría votar a las mujeres en la que hizo falta el cómputo de los votos y la declaratoria de vigencia, lo que nunca se realizó, ya que en el Partido Nacional Revolucionario se consideró que el voto femenino podría verse influenciado por los curas (Virgen, 2011); sin embargo, no fue sino hasta 1947 que se permitió a las mujeres participar en las elecciones municipales, en igualdad de condición que los varones y con el derecho de votar y ser votadas (Diario Oficial, 1947); y en 1953 por primera vez en la historia de México se le reconoce al género femenino la calidad ciudadana, con lo que formalmente se permite su participación en todas las elecciones del país (Diario Oficial, 1953). También es importante la reforma al artículo $4^{\circ}$ constitucional de 1974 que incluyó al inicio de su primer párrafo lo siguiente: "El varón y una mujer son iguales ante la ley..." (Diario Oficial, 1974).

2 En el año 2001 se reformó el artículo 2, inciso A, fracción III, de la Constitución Política de los Estados Unidos Mexicanos, quedando así: "La Nación Mexicana es única e indivisible [...] A. Esta Constitución reconoce y garantiza el derecho de los pueblos y las comunidades indígenas a la libre determinación y, en consecuencia, a la autonomía para: [...] III. Elegir de acuerdo con sus normas, procedimientos y prácticas tradicionales, a las autoridades o representantes para el ejercicio de sus formas propias de gobierno interno, garantizando la participación de las mujeres en condiciones de equidad frente a los varones..." (Diario Oficial de la Federación, 2001). Asimismo, el Código Federal de Instituciones y Procedimientos Electorales establecía en su artículo 38: "Son obligaciones de los partidos políticos nacionales: s) Garantizar la equidad y procurar la paridad de los géneros en sus órganos de dirección y en las candidaturas a cargos de elección popular"; en su artículo 218, párrafo 3: "Los partidos políticos promoverán y garantizarán en los términos del presente ordenamiento, la igualdad de oportunidades y procurarán la paridad de género en la vida política del país, a través de postulaciones a cargos de elección popular en el Congreso de la Unión, tanto de mayoría relativa como de representación proporcional"; en su artículo 219, párrafo 1: "De la totalidad de solicitudes de registro, tanto de las candidaturas a diputados como de senadores que presenten los partidos políticos o las coaliciones ante el Instituto Federal Electoral, deberán integrarse con al menos el cuarenta por ciento de candidatos propietarios de un mismo género, procurando llegar a la paridad" (Diario Oficial de la Federación, 2008).

3 En reciente reforma al artículo 41 de la Constitución Política de los Estados Unidos Mexicanos, publicada el 10 de febrero de 2014, se establece: “...Los partidos políticos tienen como fin [...] como organizaciones de ciudadanos, hacer posible el acceso de éstos al ejercicio del poder público, de acuerdo con [...] las reglas para garantizar la paridad entre los géneros, en candidaturas a legisladores federales y locales..." (Diario Oficial de la Federación, 2014).

4 Por ejemplo, el Plan Nacional de Desarrollo, que en su apartado de "Perspectiva de género" expresa como fundamental para la actual administración, garantizar la igualdad sustantiva de oportunidades entre hombres y mujeres (Plan Nacional de Desarrollo 2014-2018).

5 Por ejemplo, la Declaración Universal de los Derechos Humanos, que establece el derecho de acceso que toda persona tiene en condiciones de igualdad a las funciones públicas de su país (ONU, 1948); la Convención sobre los Derechos Políticos de la Mujer, que establece el derecho de las mujeres a ser elegibles y ocupar cargos públicos en condiciones de igualdad con los hombres, sin discriminación alguna (ONU, 1952); el Pacto Internacional de los Derechos Civiles y Políticos, que establece el derecho de los ciudadanos para tener acceso a las funciones públicas de su país en condiciones de igualdad (ONU, 1966). 
parámetro bajo el cual se puede lograr una mayor justicia en cuanto al reparto de cargos públicos y de participación de la ciudadanía femenina en los puestos de elección popular. Es un medio conceptualizado como "real" para el logro de la igualdad entre hombres y mujeres en esos aspectos políticos, es decir, a diferencia del precepto jurídico en el que se permite de manera tácita la participación de la mujer, pero no se impulsa, este se constituye en uno que sí tiene impacto en la realidad social, precisamente por plantear de manera expresa el deber de participación de la mujer, lo que se ha denominado acción positiva por cuotas. Con este trabajo pretendo sostener que la paridad de género ${ }^{6}$ infringe el principio democrático de la igualdad. Con la finalidad de lograr lo anterior he considerado los elementos esenciales de la igualdad democrática para determinar sus características específicas y los he contrastado con los de la paridad; esto con independencia de que la paridad esté logrando su objetivo primario: hacer que un mismo número de mujeres respecto del de hombres participen en los procesos electorales y ejerzan los cargos de elección popular, con los innegables beneficios sociales que esto conlleva; sin embargo, en esencia, la democracia postula la igualdad desde otro punto de vista que difiere de la igualdad que se toma como premisa para sustentar jurídicamente la paridad. También es importante la distinción entre igualdad de oportunidades para acceder a los procesos electorales y la igualdad en los resultados de esos procesos en contraste con la esencia de la igualdad democrática, esto desde el punto de vista de la justicia social y de la paridad de género.

\section{Razón de ser de la paridad de género.}

Paridad significa igualdad de las cosas entre sí (Real Academia Española), y género es el grupo al que pertenecen los seres humanos de cada sexo, entendido este desde un punto de vista sociocultural en lugar de exclusivamente biológico (Real Academia Española). La función de la paridad es igualar, por alguna razón, dos objetos en valor y sentido, por lo que dos objetos con características desiguales podrían dejar de serlo aplicando algún criterio de paridad que las torne iguales; por ello, el tratar de aplicar criterios de paridad a dos objetos que per se son iguales, carece de sentido. Es necesario determinar criterios o parámetros para establecer la paridad y su aplicación, por ejemplo, tal vez sería necesario que los dos objetos destinatarios de la aplicación de los criterios de paridad tengan algún elemento, característica o categoría en común (coincidente), o varias de ellas, con la finalidad de que se pueda determinar una igualdad inicial aproximada y cuando se vayan a aplicar los criterios de paridad ya solamente sea respecto a aquellos que contrastan o que difieren entre uno y otro de dichos objetos. Con lo anterior, se haría entonces necesaria la introducción de pocas variables paritarias para que se pueda lograr la identidad en las características, elementos o categorías de los objetos referidos. Asimismo, también podría ser necesario determinar el tipo de paridad que se desea para los objetos dados, ya que, dependiendo de la circunstancia política, social, jurídica, etc., se haría necesario agregar variables específicas (relacionadas con dichas circunstancias) para que se pueda lograr la igualdad deseada y no una igualdad absoluta o idéntica que tal vez rebasaría las intenciones últimas de la paridad.

Las cuotas se implementaron como una acción afirmativa a favor de las mujeres para que pudieran superar los obstáculos ${ }^{7}$ que les impiden participar en la política de un Estado, ello considerando que la participación femenina en ese aspecto siempre fue muy poca, tal vez debido a otras circunstancias de tipo político que tienen lugar en México. Por lo anterior, la paridad de género se ha considerado como una solución a los problemas de justicia

6 Considerándola como un mandato legal en México en cuanto a los procesos para la elección popular de cargos públicos, sin tomar en cuenta que permea en otras áreas y sectores de la sociedad.

7 Es importante aclarar que tales obstáculos son políticos e incluso sociales, pero no legales, ya que la norma jurídica no imponía -ni impone-restricción alguna a la participación femenina en los procesos de elección de cargos de elección popular ni a su eventual ejercicio. 
social, ya que si las mujeres ocupan un número determinado de cargos de elección popular entonces podrían tener la posibilidad de incluir en los planes y programas gubernamentales (y en sus decisiones públicas), aquellas políticas o acciones necesarias para la mejoría de la calidad de vida social de ese sector femenino de la población. Una de las maneras en las que se ha intentado corregir históricamente la desigualdad de la participación femenina en democracia es mediante la implementación de leyes que procuran la igualdad, como las cuotas y posteriormente la paridad, lo que también es congruente con lo establecido en el artículo $4^{\mathrm{o}}$ de la Constitución Política de los Estados Unidos Mexicanos ${ }^{8}$, esto bajo la consigna loable de que si dos objetos no son iguales (políticos, sociales y jurídicos) entonces se deben igualar con miras al beneficio social y democrático y así cumplir con los postulados de libertad e igualdad que derivan de la democracia como forma de gobierno. Esto se puede evidenciar con la obligatoriedad legal que tienen los partidos políticos de incluir en su normatividad interna la paridad electoral para postular candidatos, es decir, el mismo número de hombres que de mujeres alternados en las listas o planillas para evitar el predominio de uno de los géneros sobre el otro. ${ }^{9}$

Hay dos posturas, la primera relativa a lo innecesario de que exista la paridad, la cual se apoya en la hipótesis de que, si el sistema jurídico que regula el aspecto democrático y las elecciones es adecuado para impulsar la participación de las mujeres y también la de los hombres en un aspecto igualitario, entonces no hay necesidad de establecer cuotas ni parámetros de paridad en una sociedad que en la práctica es igualitaria; la segunda postura es la que defiende la paridad bajo el argumento de que aún no se ha alcanzado la efectiva igualdad y que sigue siendo una meta por alcanzar en un medio social en el que se adolece de la participación del sector femenino en aspectos estatales. Para poder reflexionar acerca de cuál de esas dos posturas es la más congruente democráticamente, es necesario partir del concepto de ciudadanía:

"El punto de partida de la reflexión hacia la paridad en el ámbito de la política ha sido la revisión del concepto de ciudadanía, bajo la consideración de que ésta se compone por igual de mujeres y hombres y, en consecuencia, ambos deben estar representados en porcentajes iguales en el sistema político. No se trata únicamente de cubrir una cuota mayor de cargos políticos a favor de las mujeres, sino de reconocer y respetar, de manera efectiva y en un

8 El cual establece al inicio de su primer párrafo: "El varón y la mujer son iguales ante la ley...” (Diario Oficial, 1974).

9 La Ley General de Instituciones y Procedimientos Electorales establece en su artículo 7: “...También es derecho de los ciudadanos y obligación para los partidos políticos la igualdad de oportunidades y la paridad entre hombres y mujeres para tener acceso a cargos de elección popular", el artículo 232, párrafo 3: "Los partidos políticos promoverán y garantizarán la paridad entre los géneros, en la postulación de los candidatos a los cargos de elección popular para la integración del Congreso de la Unión, los Congresos de los Estados y la Asamblea Legislativa del Distrito Federal" y en su párrafo 4: "El Instituto y los Organismos Públicos Locales, en el ámbito de sus competencias, tendrán facultades para rechazar el registro del número de candidaturas de un género que exceda la paridad fijando al partido un plazo improrrogable para la sustitución de las mismas. En caso de que no sean sustituidas no se aceptarán dichos registros"; el artículo 233: "De la totalidad de solicitudes de registro, tanto de las candidaturas a diputados como de senadores que presenten los partidos políticos o las coaliciones ante el Instituto, deberán integrarse salvaguardando la paridad entre los géneros mandatada en la Constitución y en esta Ley"; el artículo 234: "Las listas de representación proporcional se integrarán por fórmulas de candidatos compuestas cada una por un propietario y un suplente del mismo género, y se alternarán las fórmulas de distinto género para garantizar el principio de paridad hasta agotar cada lista"; y el artículo 241, párrafo 1: "Para la sustitución de candidatos, los partidos políticos y coaliciones lo solicitarán por escrito al Consejo General, observando las siguientes disposiciones: a) dentro del plazo establecido para el registro de candidatos podrán sustituirlos libremente, debiendo observar las reglas y el principio de paridad entre los géneros establecido en el párrafo 3 del artículo 232 de esta Ley..." (Diario Oficial de la Federación, 2014). 
sentido amplio, la igualdad entre mujeres y hombres [...] La necesidad de su implementación se basa en que la limitada participación de las mujeres en los niveles decisorios obstaculiza el desarrollo humano, al no incorporarse las demandas e intereses de las mujeres en todos los aspectos de la vida política, social, cultural y económica de la sociedad" (Medina, 2010).

No se debe perder de vista que el concepto de ciudadano está referido a un ente social que posee determinadas características jurídicas que no hacen referencia distintiva al género por no ser relevante, ya que su naturaleza biológica no determina factores o características indispensables para que dicha figura pueda ser reconocida o para que pueda funcionar al interior de un Estado. Es decir, el ciudadano puede ser del género femenino o masculino, ${ }^{10}$ no hay razón alguna para limitar o condicionar esa cualidad de ciudadano, y uno de los efectos de la ciudadanía -el que atañe a este trabajo- es la posibilidad de acceder a los procesos de elección popular ${ }^{11}$ en los que podría haber la posibilidad de resultar ganador. ${ }^{12}$ Se trata de una doble posibilidad: la de acceder al proceso necesario para competir por un cargo de elección y la de ganar en tal proceso con el efecto jurídico de tomar posesión del cargo y ejercerlo, pero esa posibilidad no representa -ni debe representar- la seguridad de que se gane el cargo de elección popular, ya que, de ser así, se estaría entonces, en realidad, imponiendo un resultado a priori.

El razonamiento de la autora es: si la ciudadanía se compone por igual de hombres y mujeres entonces ambos deben estar representados en porcentajes iguales en el sistema político. Sin embargo, tal proposición carece de validez por la falacia que se propone, la cual está basada, primero, en la supuesta composición "igual" de hombres y mujeres, lo que significaría que la ciudadanía está compuesta en partes iguales por unos y otras, es decir, $50 \%$ y $50 \%$, lo cual es falso y, además, difícil de verificar. Posteriormente toma esa premisa ( $\sin$ considerar lo imprecisa que puede ser) para concluir que en el sistema político deben prevalecer esos mismos porcentajes, cuando en realidad no existe una razón válida y el razonamiento citado no proporciona ninguna base por la que se justifiquen esos porcentajes, ya que de tratarse de ese criterio cuantitativo estrictamente se tendría que calcular el porcentaje preciso de representantes políticos igual con el de hombres y mujeres que componen a la ciudadanía. Por tal motivo, tal criterio cuantitativo es inoperante por lo complejo en el referido cálculo y porque, en última instancia, esa premisa no garantiza resolver el problema de fondo: propiciar una mayor participación de la mujer en las actividades políticas, ya que la participación tiene como premisa la voluntad del sujeto que se involucra en los asuntos de Estado y sin esa premisa solamente estaríamos ante una participación forzada u obliga-

10 De hecho, en el caso de México, la Constitución Política establece: "Artículo 34. Son ciudadanos de la República los varones y mujeres que, teniendo la calidad de mexicanos, reúnan, además, los siguientes requisitos: I. Haber cumplido dieciocho años, y II. Tener un modo honesto de vivir", de lo que se desprende que, al menos desde el punto de vista constitucional, no existe limitante ni restricción alguna para que, a causa del género, se les limite su acceso a los procesos de elección popular a las mujeres (CPEUM, 1917)

11 Lo que significa que el ciudadano (varón o mujer) ha reunido, desde luego, otros requisitos legales, los cuales, vale decir, son los mismos para ambos géneros, y ha reunido también (o ha satisfecho) algunos otros de carácter político (como la postulación de parte de su partido político o la demostración de haber obtenido el apoyo popular para el caso de las candidaturas independientes); éstos últimos requisitos de carácter político posiblemente no sean igualitarios con relación al género, pero tal vez la determinación partidaria para postular a más hombres que mujeres esté apoyada en otras causas que no tienen relación alguna con el género, de cualquier forma, la ley ya obliga a los partidos políticos a que postulen un mismo número de hombres que de mujeres, es decir, de forma paritaria.

12 Para ser ganador de un cargo de elección popular el sistema electoral mixto en México impone que se obtenga la mayoría relativa de los votos o un porcentaje de los mismos en atención al impacto electoral que tenga el partido que lo postuló y, para el caso de los cargos para senador por la primera minoría, aquellos candidatos que han obtenido el segundo lugar de la votación obtenida. 
da, lo cual atenta contra la esencia misma del concepto de participación. ${ }^{13}$ Sigue diciendo la autora que la necesidad de implementar la paridad de género se basa en la existencia de una limitada participación de las mujeres en el nivel político decisorio, lo que obstaculiza el desarrollo humano al no incorporarse las demandas e intereses de las mujeres en diversos aspectos de la vida. Sin embargo, esa no es la causa de que tales demandas no sean incluidas $\mathrm{o}$, al menos, la autora no lo demuestra con datos fehacientes, por lo que existe la posibilidad de que ese fenómeno de sub-representación tenga una causa diferente y la paridad de género solamente sea un paliativo superficial que no ataca dicha causa, sino solamente los resultados numéricos. ${ }^{14}$

Ahora bien, tanto hombres como mujeres se enfrentan a determinados obstáculos para poder participar (y más que ello, para decidir participar) en los procesos de elección y, eventualmente, con otros obstáculos (ajenos a su decisión) para poder ganar esa elección; lo anterior puede tener un origen diverso al meramente jurídico (el cual ya quedó establecido que no lo hay), por ejemplo, las circunstancias personales del ciudadano relativas a su entorno laboral, familiar, escolar, etc., o también derivadas de su educación, cultura general, idiosincrasia, religión, preferencias políticas, etc., o a cuestiones aún más personales - o físicas-, como aquellas relativas a la salud, la edad, la apariencia, la estatura, el color de piel, etc., todo lo anterior afecta a la decisión final del ciudadano sobre si participar o no, con lo que el universo de causas que afectan su decisión para participar en procesos electorales, o que la impiden, se amplía. Dentro de todas esas causas, es razonable pensar que tanto el sector femenino como el masculino de la ciudadanía juegan un rol social, laboral, político, etc., que les genera determinadas circunstancias que podrían razonablemente erigirse en verdaderos obstáculos para participar, aún a pesar de que la ley no les limita su acceso (más allá de los requisitos legales para el voto activo y el voto pasivo). La discriminación derivada del género es una de las razones por las que se establecen las cuotas y también la paridad, ya que tal discriminación significa la obstaculización en el intento de las mujeres por acceder a un proceso electoral en el que pudieran resultar ganadoras de un cargo de elección popular. En caso contrario, es decir, si no existe la discriminación por género entonces las mujeres tienen libre acceso a los procesos necesarios para alcanzar ese objetivo, lo que se traduciría en una igualdad real de oportunidades (pero no de resultados). Sin embargo, la igualdad real no es la única relevante, ya que también está la igualdad jurídica y la igualdad democrática. Consecuentemente, la razón de ser de la paridad de género es (además del discurso mediático y político) privilegiar el resultado de la elección y no el proceso en sí, ya que con la paridad se asegura que la mitad de los cargos públicos sean ocupados y ejercidos por mujeres, mientras que lo importante debería ser el proceso de elección en el que se privilegie la libertad de acudir a las urnas (ya sea como votante activo o como votante pasivo) y que por virtud de decisión mayoritaria (esencia de la democracia) se elija a quienes ocuparán tales cargos.

13 Participación: acción y efecto de participar (Real Academia Española); participar: dicho de una persona, tomar parte en algo (Real Academia Española). Ciertamente la participación puede considerarse desde dos puntos de vista: la voluntaria y la obligada; sin embargo, esta última atenta contra la esencia misma de la democracia, ya que uno de sus principios es la libertad que implica la posibilidad de optar o no por tomar determinada decisión de entre una serie de opciones que se le presentan al ciudadano, pero también existe la posibilidad de que tales opciones no satisfagan sus intereses o su voluntad y se abstenga de adoptar alguna decisión. En un escenario socio-político en el que al ciudadano se le obliga a optar por alguna de las opciones que se le presentan sin que las mismas sean satisfactorias, se puede incurrir en los peligros de la manipulación en el sistema de elecciones a favor de un sector de la política que lo controla; con esto, obligar a la mujer a participar puede convertirse en un problema mayor que aquel que se pretende solucionar: la participación de las mujeres para que sean representadas en sus intereses políticos, sociales, económicos, etc.

14 Los resultados estadísticos para demostrar la eficacia de las instituciones jurídicas, políticas y gubernamentales, ha sido un instrumento muy usado por el sector gobernante en México durante los últimos años; las estadísticas tergiversadas incluyen violencia, elecciones y pobreza (Pascoe, 2016). 


\section{Esencia de la igualdad democrática}

Igualdad significa la conformidad de algo con otra cosa en naturaleza, forma, calidad o cantidad, también correspondencia y proporción que resulta de muchas partes que uniformemente componen un todo (Real Academia Española). Este concepto ha sido extensamente analizado por doctrinarios y autoridades (estas últimas desde su producto legislativo o jurisdiccional) pero no existe un acuerdo en sus definiciones, algunas de ellas confusas, incongruentes o hasta contradictorias. Autores como Ronald Dworkin (2014: 422-423) ponen de relieve lo anterior al demostrar que el concepto de igualdad tiene una característica criterial, con diversas aristas definitorias, mismas que se frustran bajo la perspectiva que debate la importancia de la igualdad frente a otros factores hipotéticamente más importantes (o tal vez menos), como la prosperidad para las clases medias, es decir, el debate acerca de la importancia que tiene el hecho de que todo el mundo tenga -desde la perspectiva material o económica- lo mismo. Como punto de partida, el autor refiere un derecho abstracto apoyado en la igualdad de oportunidades y no de resultados, ya que los resultados son un producto de los méritos personales. Tal es el derecho a la igual consideración y respeto relacionado a la administración de las instituciones políticas:

"los individuos tienen derecho a igual consideración y respeto en el diseño y administración de las instituciones políticas que los gobiernan. Se trata de un derecho sumamente abstracto, respecto del cual alguien podría argumentar, por ejemplo, que queda satisfecho por las disposiciones políticas que aseguran igualdad de oportunidades para ocupar cargos sobre la base del mérito" (Dworkin, 1989: 272).

Lo anterior tiene plena aplicabilidad en cuanto a los procesos electorales se refiere, ya que tienen como finalidad preponderante precisamente la administración de los parámetros políticos, jurídicos y sociales que gobiernan al interior de un Estado, y que, desde luego, los ciudadanos (al menos lo racionales) tienen el interés de conocer para participar en ellos. Se trata, dice el autor (Dworkin, 1989: 273), de un derecho en abstracto que se tiene a la igual consideración y al igual respeto, mismo que a su vez tiene su fundamento filosófico en la teoría rawlsiana referida a la posición original (Rawls, 2004) que las personas tienen en una determinada sociedad y que marca la pauta en cuanto a la cantidad de justicia social de que puedan gozar. Para comprender cabalmente la igualdad democrática es inevitable hacer referencia al concepto de justicia como equidad ${ }^{15}$ para lo cual será pertinente la siguiente definición:

"podemos decir que la justicia como equidad descansa sobre el supuesto de un derecho natural de todos los hombres y todas las mujeres a la igualdad de consideración y respeto, un derecho que poseen no en virtud de su nacimiento, sus características, méritos o excelencias, sino simplemente en cuanto seres humanos con la capacidad de hacer planes y de administrar justicia" (Dworkin, 1989: 274).

Con base en lo anterior, la igualdad de consideración y respeto se erige en una premisa insoslayable para el tratamiento de la justicia desde su perspectiva de equidad. La misma

15 Mientras tanto, "equidad" se define de varias formas: Igualdad de ánimo; bondadosa templanza habitual, propensión a dejarse guiar, o a fallar, por el sentimiento del deber o de la conciencia, más bien que por las prescripciones rigurosas de la justicia o por el texto terminante de la ley; justicia natural, por oposición a la letra de la ley positiva; moderación en el precio de las cosas o en las condiciones de los contratos y disposición del ánimo que mueve a dar a cada uno lo que merece (Real Academia Española). 
consideración y el mismo respeto para hombres y mujeres, significa que las acciones que son resultado de las interacciones entre ellos deben tener su fundamento en una misma cantidad de atención que implica otorgarle una misma cantidad de importancia ${ }^{16}$ tanto a uno como a otro de los géneros, es decir, su conformidad en calidad y cantidad de atención y de importancia que se da a las acciones, pensamientos, reclamos, intenciones, participaciones, etc., tanto del hombre como de la mujer. Asimismo, dichas acciones deben contener determinada deferencia para que reciban el miramiento ${ }^{17}$ necesario y recíproco entre hombres y mujeres de acuerdo a sus condiciones y características. Aquí cabe preguntar ¿La igualdad democrática significa mismo número de hombres y de mujeres en el ejercicio de los cargos de elección popular? Tal cuestión está íntimamente ligada con la búsqueda de la esencia de la igualdad democrática, es decir, se requiere saber cuál es el aspecto medular y característico de la igualdad en un régimen de democracia, que lo distinga de otros tipos de justicia social o de equidad política derivada o destinada para la forma de gobierno en la que se construyen los cargos públicos por virtud de procesos de elección popular. La idea del mismo número de hombres y de mujeres en el ejercicio de cargos populares contrasta con la idea de la misma consideración y respeto para que ambos géneros accedan a los procesos de elección popular y, eventualmente, ejerzan el cargo respectivo. Que todo el mundo deba ser tratado con la misma consideración y respeto es una idea que se erige en un principio de igualdad de Dworkin, quien ...considera que uno de los objetivos principales del sistema jurídico es controlar y limitar la acción del gobierno. Pero, la defensa de los derechos individuales... [y] ... del derecho a la igual consideración y respeto- no le lleva a posiciones conservadoras sino progresistas (Calsamiglia, 1989: 23).

Ahora bien, según la tesis de la posición original de Rawls (2004: 25), en una sociedad racional se obligaría a ciudadanos racionales a elegir situaciones de justicia, pero el velo de la ignorancia les impide verificar si tales elecciones son las adecuadas una vez que dicho velo ha sido retirado y que se pueden constatar las circunstancias reales en las que se vive; tal elección se da gracias a la celebración de un hipotético contrato social entre hombres y mujeres que pertenecen a una sociedad. En contraste, Dworkin (1989: 234) pone en duda que tal posición original sea diseñada tomando en cuenta las particularidades de hombres y mujeres relativas a sus circunstancias sociales específicas: “...la posición original difiere de ellos en su descripción de las partes, que en este caso son hombres y mujeres de gustos, talentos, ambiciones y convicciones comunes...", esas particularidades provocan una variación en su trayectoria como ciudadanos; sin embargo, un punto de coincidencia entre ambos autores es en cuanto a la libertad política compatible con la libertad semejante para todos:

"Rawls intenta demostrar que, si esos hombres y mujeres son racionales y
actúan únicamente en su propio interés, escogerán sus dos principios de
justicia, que estipulan, aproximadamente, que cada persona debe tener la
mayor libertad política compatible con una libertad semejante para todos, y
que las desigualdades - en el poder, la riqueza, los ingresos y otros recursos-no
deben existir, a no ser en la medida en que actúen en beneficio absoluto de los
miembros de la sociedad que peor están" (Dworkin, 1989: 234).

Con lo anterior encontramos un nuevo elemento que se inserta en la discusión sobre la esencia de la igualdad democrática: las desigualdades solamente están justificadas cuando

16 "En consideración a" es una locución preposicional que significa "en atención a", y "ser de consideración algo" es una locución verbal que significa "ser de importancia, monta o consecuencia", asimismo, "tomar en consideración algo" significa "considerarlo digno de atención" (Real Academia Española).

17 "Respeto" proviene del latín respectus que significa atención o consideración y también es "miramiento" (acción de mirar, atender o considerar algo), "consideración" o "deferencia" (adhesión al dictamen o proceder ajeno) (Real Academia Española). 
produzcan un beneficio a los miembros de la sociedad menos afortunados; sin embargo, ¿Es equitativo aplicar los dos principios de justicia de Rawls? en caso afirmativo, el fundamento de dicha afirmación está en la afirmación/base de que las personas en la posición original que habrían aceptado la aplicación de esos dos principios de justicia los aceptarían también cuando/aunque hayan cambiado las circunstancias:

"El argumento de la posición original es muy diferente. Si suponemos que defiende la equidad de aplicar los dos principios, debemos suponer que sostiene que porque un hombre habría dado su acuerdo a ciertos principios si le hubieran preguntado de antemano, es justo aplicarle esos principios más adelante, en circunstancias diferentes y cuando él no les da su acuerdo" (Dworkin, 1989: 237).

Es razonable pensar que las personas toman decisiones a cada momento de su vida y que dichas decisiones están ligadas a sus sentimientos, circunstancias y medio social en el que se encuentran insertos, y que por esas razones podrían tomar determinadas decisiones que pueden variar de un momento a otro a pesar de haber tenido una opinión diferente en un momento previo, máxime si no fue una decisión comprometida por un acuerdo de voluntades, lo que le otorgaría legalidad y legitimidad a su voluntad cambiante. De ahí la importancia de la igualdad democrática y su esencia que está relacionada con la igualdad jurídica y también política, categorías democráticas que la erigen en un verdadero principio, aunque hay autores que la postulan como un valor de la democracia:

"La igualdad jurídica y política de todos los ciudadanos es el segundo valor fundamental de la democracia moderna. Este valor no significa que se cancelen todas las diferencias o incluso desigualdades de corte económico, social, cultural o físico, sino que ninguna de tales diferencias o desigualdades puede legitimar el dominio de unos seres humanos sobre otros y, por ende, la preeminencia política de los primeros sobre los segundos" (Salazar y Woldenberg, 2012: 30).

Y no se cancelan todas las desigualdades -inevitables- por virtud de las circunstancias específicas de cada persona que ya se abordaron antes. Un elemento de interés que los autores incluyen en el texto citado es que tales desigualdades inevitables no pueden ser elemento legitimador de dominio o preeminencia de unos seres humanos sobre otros ni de hombres sobre mujeres o viceversa:

"Por eso, es un principio básico de los procedimientos democráticos que cada ciudadano tenga derecho a un voto y sólo a un voto, y que ningún voto valga más que los demás. De esta manera, en el momento de emitir los sufragios desaparecen las diferencias intelectuales, físicas o socioeconómicas, y cada votante tiene exactamente el mismo peso en los comicios, sin importar su ocupación, su sexo, su fortuna o sus capacidades personales" (Salazar y Woldenberg, 2012: 30).

Se trata de una igualdad del voto independientemente de las capacidades o características biológicas, es decir, sin importar el género del votante, con lo que el razonamiento que pretende sustentar la paridad pierde validez al ser imposible que tanto hombres como mujeres emitan más votos que los legalmente permitidos o con mayor valor, con lo que -al menos desde jurídicamente- se evita la desigualdad de género. En consecuencia, a pesar de que siempre es deseable que exista la igualdad, ésta no debe ser considerada de manera absoluta por el riesgo de las implicaciones indeseables que potencialmente podrían ocurrir 
al afectar, por ejemplo, al pluralismo o a la diversidad: La igualdad democrática [...] no se opone a las diferencias sociales y culturales: tampoco impide las distinciones por mérito o por capacidades de determinado tipo. No es una igualdad igualitarista o uniformadora, que pretenda abolir el pluralismo y la diversidad [...] Es [...] una igualdad dentro de la libertad y para la libertad [...] dentro y para el pluralismo y la diversidad (Salazar y Woldenberg, 2012: 31).

\section{Paridad e igualdad: conceptos excluyentes}

Con la libertad se puede válidamente suponer que los ciudadanos (hombres y mujeres igualmente, porque la ley no inhibe la participación de uno u otro) pueden optar o no por acudir a los comicios, como de hecho sucede, ya sea en calidad de electores o de candidatos. Esa libertad congruente con la igualdad es contraria a la paridad de género que obliga a que el $50 \%$ de los cargos públicos sean ocupados por mujeres:

"Equidad en política significa hallar los procedimientos políticos (métodos para elegir funcionarios y hacer que sus decisiones sean responsables para el electorado) que distribuyen el poder político de la forma adecuada. Esto se entiende [...] como procedimientos y prácticas que atribuyen a todos los ciudadanos más o menos la misma influencia en las decisiones que los gobiernan" (Dworkin, 2012: 124).

Equidad y decisión son dos aspectos de una misma circunstancia social, ya que los procedimientos electorales a los que se ven sometidos los ciudadanos -hombres y mujeresdependen, per se, de una tendencia voluntaria que se traduce en una decisión de participar en tales procesos, por lo que la equidad se verifica al momento de otorgarles las mismas condiciones legales, políticas y sociales para que puedan decidir si participan o no. Aquí el concepto de justicia tiene que ser adoptado para comprender que las personas tienen el derecho a igual consideración y respeto, lo que implica que también la decisión tomada por los ciudadanos o ciudadanas sea respetada independientemente de que sea en el sentido de participar o de abstenerse, lo que en última instancia produce el concepto de igual ciudadanía:

"la estructura básica [de la sociedad] deberá ser evaluada [...] desde la posición de igual ciudadanía. Esta posición se define por los derechos y libertades que exigen el principio de igual libertad y el principio de la justa igualdad de oportunidades. Cuando los dos principios se satisfacen, todos son ciudadanos iguales y, por tanto, todos ocupan esta posición” (Rawls, 2004: 99).

Igual libertad y justa igualdad de oportunidades que, satisfechos ambos, permiten hablar de ciudadanía igual. El siguiente párrafo da una idea de lo injusto que puede ser una política que atienda solamente a la utilidad del resultado y no al proceso en sí:

“idealmente, una constitución justa será un procedimiento justo dispuesto de manera que asegure un resultado justo. El procedimiento sería el proceso político regido por la constitución, el resultado la legislación promulgada, mientras que los principios de justicia definirían un criterio independiente, tanto para el procedimiento como para el resultado. En la prosecución de este ideal de justicia procesal perfecta, el primer problema es idear un procedimiento justo. Para hacerlo las libertades de una ciudadanía igual tienen que ser incorporadas y protegidas por la constitución. Estas libertades incluyen la libertad de conciencia y de pensamiento, la libertad personal y la igualdad de 
derechos políticos. El sistema político [...] no sería un procedimiento justo de no incorporar estas libertades" (Rawls, 2004: 189).

Resulta interesante la aseveración respecto a que la ciudadanía igual tiene su fundamento en un procedimiento justo con las libertades ciudadanas protegidas constitucionalmente. Al respecto, la paridad de género contradice lo anterior, ya que se trata de una regla establecida en cuanto al procedimiento de selección de titulares de órganos públicos en la que la igualdad se confunde con la paridad: igualdad atiende a la libertad de los ciudadanos de poder participar en procesos comiciales, ya sean hombres o mujeres, en un procedimiento que se vuelve justo al atender la libertad de decisión, mientras que paridad atiende al resultado - paritario- y omite respetar la toma de decisiones personales de los ciudadanos o ciudadanas. Continúa el autor reflexionando acerca de la practicidad del procedimiento, pero con la consecuencia de un resultado injusto y, a pesar de que no se puede garantizar un sistema procesal completamente justo, se puede realizar un acercamiento seleccionando de las disposiciones procesales justas y practicables aquellas con una mayor probabilidad de producir un resultado justo (Rawls, 2004: 189). Una política pública justa, referida a los procesos de elección al interior de un Estado, debe implementar procedimientos justos diseñados de tal manera que aseguren un resultado justo. En este aspecto habría que revisar si la paridad de género es una política justa en términos de lo justo que pudiera ser el procedimiento empleado y también el resultado obtenido, ya que con la paridad de género se está privilegiando el resultado - paritario- mientras que el proceso se vulnera al afectar la igualdad de oportunidades. Por eso hay autores que estiman a la ciudadanía como un presupuesto básico que existe en la sociedad moderna compuesta de individuos con capacidad de discernir racionalmente entre las ofertas políticas que le son presentadas (Salazar y Woldenberg, 2012: 43-44), e indica un concepto básico de igualdad: las capacidades de raciocinio, de tomar una decisión o de ser votado, no dependen del género. En efecto, las habilidades ciudadanas (relacionadas con votar y ser votado) no dependen de las habilidades inherentes a cuestiones biológicas como lo es el género, por lo que no hay razón alguna (relacionada con el ejercicio de tales derechos ciudadanos, desde luego) para que se obligue a la cuota paritaria en la ocupación y ejercicio de los cargos públicos de elección popular. Otro caso diferente es que la labor que se vaya a desarrollar tenga una estrecha relación con tales características biológicas y que el género sea entonces una característica sine qua non para su realización.

Dowrkin (2014: 432) establece, como una de las respuestas al desafío de la igual consideración, aquellas que: ....apuntan a igualar a la gente en términos de beneficios sociales, bienestar o capacidad de acuerdo con alguna concepción de lo que cuenta como bienestar o de las oportunidades o capacidades que son importantes. Apuntan, por ejemplo, a hacer a la gente $[. .$.$] igualmente exitosa conforme a sus propios puntos de vista...; pero, ¿las políticas$ de paridad apuntan a esto? Sigue diciendo el autor:

"si una comunidad se propusiera igualar a todas las personas en cualquiera de estos productos relacionados con el bienestar, estaría imponiendo necesariamente a todas su juicio colectivo acerca de qué vidas son buenas y cómo vivir bien. Por otra parte, aniquilaría la responsabilidad personal de manera aún más decisiva en otro aspecto: apuntaría a garantizar que todas las personas fueran iguales en el producto de bienestar designado, cualesquiera que fueran las elecciones que ellas hubieran hecho o los riesgos que hubiesen corrido. La responsabilidad personal no valdría casi nada" (Dworkin, 2014: 432-433).

Igualdad en "el producto de bienestar designado" que aniquila la posibilidad de tomar una decisión razonada bajo la imposición de un "juicio colectivo", es la decisión a priori, 
no razonada por los ciudadanos destinatarios, de qué vidas son buenas y cómo vivir bien, en palabras del autor, pero aplicado al tema que nos importa: la paridad de género en las elecciones es una decisión impuesta no razonada acerca de qué género de ciudadanos toman la decisión libre de participar para ejercer cargos de elección popular. Por supuesto que aquí no combato la aptitud, lo que pongo a discusión es la determinación apriorística del resultado de las elecciones. El autor concluye: "Una comunidad que respeta la responsabilidad ética personal debe concentrarse en una distribución equitativa de los medios cuando establece su ordenamiento político. Debe dejar la elección de los fines en manos de sus ciudadanos, uno por uno" (Dworkin, 2014: 433). Por ello, los poderes estatales cuyas políticas públicas propugnan por la paridad de género y que la han llevado a nivel de mandato constitucional y legal, difícilmente se puede afirmar que respeten esa responsabilidad ética personal de los ciudadanos y, contrariamente, se puede concluir que se les coarta su derecho de elección y, por tanto, hace nugatorio el principio democrático de igualdad.

Por otro lado, en una interesante reflexión doctrinal sobre las cuotas femeninas (Aguiar, 2001: 30) se afirma que su papel es reducir el riesgo al que se enfrentan las mujeres que quieren acceder a funciones y cargos públicos y lo hace, dice, igualando la probabilidad de éxito para hombres y mujeres y no beneficiando a las mujeres por el simple hecho de serlo. Sin embargo, no iguala la probabilidad de éxito, ya que la igualación no es en cuanto a esas probabilidades, pues éstas pueden o no significar la obtención de la meta, mientras que con las cuotas se asegura, no la probabilidad, sino el éxito en el logro de la misma (que consiste en que las mujeres accedan a cargos de elección popular). Sigue diciendo el autor (Aguiar, 2001: 30) que la cuota es la medida que asegura el cumplimiento del principio de igualdad, es decir, del principio de igual respeto y consideración en el acceso a funciones y cargos públicos y que una concepción sustantiva del ideal de ciudadanía debe ser capaz de contemplar la existencia de mecanismos que impidan la discriminación social. Sin embargo, igual respeto y consideración no implica necesariamente el deber de otorgar igual número de cargos o de responsabilidades, sino de que la estructura gubernamental y procedimental le otorgue a las mujeres igual atención e importancia que a los hombres en esos procesos de elección popular, con el objetivo de que tengan la misma posibilidad de ganar alguno de esos cargos y de ejercerlo; sin embargo, esto último depende -o al menos debe dependerde la decisión exclusiva del resto de la ciudadanía por medio del sufragio. ${ }^{18}$ La cuota es un medio para salvaguardar el derecho colectivo de las mujeres a participar en la vida pública sin discriminación y ese derecho colectivo ...lo ejercen mujeres concretas que pueden optar a funciones y cargos públicos con una probabilidad de éxito a priori similar a la de los hombres, esto es, sólo limitada por sus capacidades individuales, no por su pertenencia a un grupo social vulnerable (Aguiar, 2001: 30). ${ }^{19}$ Aquí, el concepto de probabilidad está mal manejado por el autor e intenta salvar su esencia diciendo que es a priori, sin embargo, una probabilidad a priori tiene el mismo efecto que la probabilidad a posteriori: solamente crea la idea de que puede haber éxito en la meta alcanzada con una mayor intensidad pero sin ser contundente en cuanto a su alcance, eso es una probabilidad y lo otro es una certeza, una seguridad, un designio e, incluso, una imposición arbitraria.

Ahora bien, habría que revisar objetivamente el supuesto poder de los hombres sobre las mujeres, en qué consiste, cómo y en cuántos casos se ha ejercido y si en los casos en los que no se ejerce estaría entonces justificado intervenir estatalmente imponiendo una cuota de

18 Esto puede dar pauta para el siguiente planteamiento: ¿Es discriminación rechazar o no postular a un ciudadano de determinado género a un cargo público de elección popular en razón de su incompetencia o falta de preparación para ejercerlo? Para responder esto sería necesario definir con mayor detalle lo que es la discriminación, lo cual excede los propósitos de este artículo.

19 Sin embargo, existe la duda acerca de la existencia de tal limitación por causa de su pertenencia a un grupo social, lo cual también excede los propósitos de este artículo. 
género; lo anterior en virtud de que hay una diferencia entre la posibilidad real de acceder a los procesos de elección y la certeza o seguridad de que se va a ganar y, eventualmente, ejercer el cargo respectivo. En este caso, lo que se debe atacar no es el resultado, sino los obstáculos que impiden alcanzarlo:

"Si la aplicación de criterios meritocráticos no es factible aún por no darse las condiciones de partida de estricta igualdad de oportunidades que el mérito requiere, lo que se debe hacer es, como apunta el Tribunal Constitucional italiano [...] 'levantar los obstáculos que impiden a las mujeres alcanzar resultados determinados' ${ }^{20}$ en lugar de 'atribuirles directamente esos mismos resultados"” (Aguiar, 2001: 33).

No se puede negar que la cuota es una herramienta útil para el logro de objetivos sociales loables, ya que soluciona muchos de los problemas que se viven en los estados contemporáneos, sin embargo, ese hecho no implica que las cuotas constituyan una especie de panacea conceptual cuya ratio sea congruente con la de los principios democráticos, sobre todo el de igualdad. Si las cuotas no son concordantes con el principio democrático de igualdad, las políticas de paridad lo son menos aún, ya que la imposición de postular hombres y mujeres en la misma cantidad y orden en las listas electorales tiene como consecuencia inevitable el ejercicio del cargo distribuido en partes iguales para ambos géneros. Aquí surge la siguiente cuestión: ¿Se debe supeditar el mérito y las capacidades a la paridad de género? Para esto se debe determinar qué es más importante: el mérito o la paridad, y ya contestado lo anterior se puede calificar de legítimo o no el mandato de paridad en la legislación y en la Constitución. La base de la democracia es la posibilidad de que cualquiera pueda acceder a los cargos de elección popular y ahí se encuentra inserta, en un extremo, la posibilidad de que solamente hombres o solamente mujeres ocurran a los procesos democráticos de elección, los ganen y ejerzan los cargos. Si afirmamos que los ciudadanos electos deban ser los que mayores méritos reúnan, tal vez incurramos en el error de la meritocracia, pero los postulados de la democracia permiten que el ciudadano tenga la posibilidad de elegir de entre varias opciones al candidato (o candidata) que mejor satisfaga las necesidades del cargo al que está postulado, y ahí es donde entra la necesidad de que el mérito derivado del esfuerzo personal sea el parámetro justo para otorgar la preferencia en una competencia democrática igual. De esto surgen dos opciones: en caso de considerar más importante que los miembros de una sociedad excluidos de dicho parámetro sean incluidos en el ejercicio del poder público, entonces el mérito se debe supeditar a las cuotas, pero en caso de que lo más importante sea la capacidad para cumplir con el cargo, entonces las cuotas y el criterio de paridad se deben supeditar a la capacidad y al mérito. Sin embargo, si consideramos que la finalidad última de un Estado democrático es la satisfacción de las necesidades de su pueblo y que es más probable que ese objetivo se logre con alguien con mayores capacidades y méritos, entonces los candidatos electos deben ser los que posean tales características.

Por otro lado, sería pertinente analizar hasta qué punto es justo que otros miembros de la sociedad (quienes desde la posición inicial resultaron afortunados) deban sacrificar parte de sus privilegios (involuntarios, cabe decir, ya que no existió de por medio una competencia para obtener una mayor ventaja en la posición inicial) a favor de aquellos a quienes la casualidad (la biología, la herencia, lugar de nacimiento, etc.) no favoreció. Lo utópico es una sociedad homogénea en la que no existan las desigualdades. Ese es el consenso en cuanto al discurso político relacionado con la paridad de género. Por ello, la desigualdad social es un fenómeno que se pretende atacar desde las políticas públicas y desde la regulación legal,

20 Aquí el autor se refiere a la sentencia de la Corte Constituzionale italiana número 422, de 6-12 de septiembre de 1995. 
al menos en lo que corresponde a los factores que son regulables y no en cuanto aquellos que no lo son o que por sus características son muy difíciles de regular (circunstancias relacionadas con aspectos más internos del ciudadano, como sus preferencias, su nivel educativo, su ideología, etc.). Además, la desigualdad social se erige en un concepto que para su comprensión y aplicación debe relacionarse y compararse con otros conceptos sociales o con aquellos relacionados con la justicia y la equidad o sus diferentes categorías: "Desigualdad social es un concepto relacional o comparativo. Significa la existencia de distintas oportunidades en el acceso, posesión, control y disfrute de recursos y poder, derivadas de diferentes condiciones, contextos y trayectorias" (Antón, 2013). Esa idea de oportunidad es recurrente en la definición de la justicia social que hace referencia a la igual consideración y respeto que aseguran igualdad de oportunidades para ocupar cargos de elección popular, lo cual se relaciona y se compara con las diversas condiciones y contextos bajo las que el ciudadano se encuentra inserto en determinada sociedad, así como su trayectoria en la misma: dependiendo de las circunstancias en las que se encuentre en su posición original o aun considerando que sea la misma respecto a los demás ciudadanos que se integran a la sociedad, su desarrollo dentro de la misma ${ }^{21}$ puede variar las oportunidades reales que tenga para poder participar en los procesos de elección popular produciendo una variación en las oportunidades para lograr la posesión y ejercicio de un cargo público.

Si consideramos que oportunidad es el momento o circunstancia conveniente para algo (Real Academia Española), entonces el factor importante en cuanto a la igualdad democrática lo es el concepto de mismas oportunidades, el cual significa que, bajo la igualdad democrática, hombres y mujeres deben tener los mismos momentos y las mismas circunstancias que sean convenientes para el logro de las metas democráticas, que en este caso se trata de la postulación y eventual ocupación y ejercicio de cargos públicos de elección popular. De ahí en adelante, el único factor que debe ser sometido a revisión para el logro de tales metas es el relativo a las capacidades y habilidades individuales del ciudadano: "Si todo el mundo tiene, de hecho, las mismas oportunidades, el mérito puede resultar un criterio adecuado para la obtención de ciertos recursos..." (Aguiar, 2001: 33); el contraste con lo anterior surge cuando no existan las mismas oportunidades, en cuyo caso habrá que introducir cambios, ya que "...un criterio puramente meritocrático puede provocar resultados injustos si la situación de partida no es igualitaria..." (Aguiar, 2001: 33). Por tanto, se tienen dos escenarios: el primero es aquel en el que la posición inicial es la misma para todas las personas y, por ende, la justicia social inicia en ese punto en el que no existe ninguna ventaja que pudiera variar la situación de justicia y en su momento, la de igualdad democrática; y el segundo en el que la posición inicial no es la misma para todas las personas con la razonable consecuencia de que exista una variación en cuanto a la justicia social y a la igualdad democrática. Hasta aquí pareciera que la igualdad de oportunidades depende de la igualdad en la posición original de los ciudadanos, en cuyo caso estaríamos ante una justificación de la regla de paridad que garantiza el resultado en cuanto al ejercicio de los cargos de elección popular por parte de ambos géneros, sin embargo, una posición original igualitaria es una situación hipotética que difícilmente se podría dar en sociedades plurales, por lo que la igualdad de oportunidades se puede razonablemente justificar únicamente con el establecimiento de los mismos momentos y circunstancias convenientes para ambos géneros. El autor citado plantea la siguiente interrogante: "La cuestión radica, pues, en considerar si el mérito es un criterio absoluto que invalida la aplicación de cuotas, o si pueden ser compatibles de alguna forma" (Aguiar, 2001: 33); lo que se responde diciendo que el mérito es un criterio -si bien no es absoluto, ya que esa característica depende de otros factores epistémi-

21 Por ejemplo, su esfuerzo en recibir una mayor educación o en trabajar más y divertirse menos, lo que se puede traducir en tiempo dedicado a actividades que contribuyen o no al logro de esas metas públicas; todo ello a causa de sus preferencias e intereses personales. 
cos- incompatible con las cuotas y, desde luego, con la paridad, ya que una posición inicial ideal no es probable ${ }^{22} \mathrm{y}$, por otro lado, los intereses personales del ciudadano pueden ser la causa de una trayectoria cuya meta no sea necesariamente la ocupación de un cargo público de elección popular.

Asimismo, habría que determinar si el ejercicio de un cargo público de elección popular posee una finalidad inherente al género o si, por el contrario, su finalidad es inseparable de otras circunstancias que no dependen o que no tienen relación con el género, para de ahí poder determinar la necesidad de las cuotas o de la paridad en el ejercicio de la función pública. En el caso de los cargos de elección popular, la finalidad primero es de representación, segundo de solución a los problemas sociales; de ahí que la cuestión giraría en torno a ¿la paridad garantiza el cumplimiento de esas finalidades? Si es así entonces la paridad es adecuada, en caso contrario, no lo es. Ahora bien, la representación que se ejerce no es en relación al género, es decir, los detentadores de cargos públicos de elección popular no son representantes solamente del sector ciudadano que corresponde a su género, sino de toda la ciudadanía, ${ }^{23}$ lo anterior en virtud de su carácter universal, por lo que el argumento de que las mujeres ciudadanas quedan sub-representadas al haber menos mujeres ejerciendo cargos públicos queda invalidado. Se debe dar prioridad al género menos representado (sobre todo en sociedades como la mexicana en la que ha habido una discriminación histórica en ese sentido), siempre que las diferencias cualitativas entre el más representado y el menos representado no sean tan impactantes en las exigencias y necesidades objetivas a que atienden las finalidades de la elección y de su ejercicio en el cargo público. Un ejemplo es la declaración de ilegalidad de la ley sueca que permite el acceso femenino con menor cualificación:

“'El método de selección es desproporcionado', indica la sentencia. 'Dar una prioridad a las mujeres con igual cualificación que los hombres no es contrario al derecho comunitario, si lo que se busca es establecer un equilibrio entre sexos', reconoce el tribunal, pero deja claro que tiene que garantizarse 'una apreciación objetiva de cada candidatura individual'. La igualdad entre mujeres y hombres es una de las asignaturas pendientes en la Unión Europea [...] El tribunal constató, tras examinar los mecanismos de designación de candidatos para cargos públicos, que 'la legislación sueca permite dar una prioridad a un candidato perteneciente a un sexo infrarrepresentado que, aunque suficientemente cualificado, no tiene la misma cualificación que la de los otros candidatos del sexo opuesto', y añade que el proceso de selección en causa 'no responde a criterios claros y ciertos'. 'No se puede descartar el riesgo de una apreciación arbitraria de la cualificación de los candidatos', concluye" (El País, 2000).

Otro ejemplo en el que se reflexionó acerca de lo justo que puede resultar el criterio de paridad o de cuotas femeninas (con base en el estudio de la discriminación positiva de la

22 "En la justicia como imparcialidad, la posición original de igualdad corresponde al estado de naturaleza en la teoría tradicional del contrato social. Por supuesto que la posición original no está pensada como un estado de cosas históricamente real, y mucho menos como una situación primitiva de la cultura. Se considera como una situación puramente hipotética caracterizada de tal modo que conduce a cierta concepción de la justicia [aquí el autor hace referencia a la formalidad de Kant en cuanto al acuerdo original hipotético]. Entre los rasgos esenciales de esta situación, está el de que nadie sabe cuál es su lugar en la sociedad, su posición, clase o status social; nadie sabe tampoco cuál es su suerte en la distribución de ventajas y capacidades naturales, su inteligencia, su fortaleza...", (Rawls, 2004: 25).

23 Hombres y mujeres e incluso personas con preferencias sexuales diferentes. De hecho, la representación debe comprender a toda la población y no solamente a un sector de ésta, ya que de lo contrario estaríamos ante una representación fragmentada o cercenada, lo cual atenta contra su esencia. 
mujer) en el ejercicio de un determinado puesto laboral, lo es el del Tribunal Europeo de Justicia:

“en 1991, cuando en Bremen (Alemania) salió a concurso la plaza de director de jardinería. Optaron Eckhardt Kalanke y una mujer. Una entidad de arbitraje dio el puesto a la candidata femenina, ateniéndose a una ley que preveía favorecer a las mujeres en tanto estuviesen menos representadas en los cargos directivos. Aconsejado por su abogado, Kalanke reclamó a la Administración de Bremen por sentirse discriminado en razón de su sexo. Por fin, el 17 de octubre de 1995, el Tribunal Europeo falló a favor de Kalanke y consideró que la discriminación positiva de la mujer es ilegal cuando se aplica de forma 'absoluta e incondicional' [...] En consecuencia, el 5 de marzo de 1996 el Tribunal Federal de Alemania estipuló que el sistema de cuotas de Bremen no se ajustaba al derecho comunitario europeo y, por tanto, tenía que ser modificado. Sin embargo, el fallo federal no concedió a Kalanke derecho a ocupar de inmediato la plaza laboral, sino que exigió una nueva convocatoria basada en criterios de capacitación y no favorables automáticamente a una mujer" (El País, 2000).

"No favorables automáticamente a una mujer", lo que la paridad significa es exactamente eso: favorecer al sector femenino de forma automática, sin revisar otros criterios cualitativos, con la justificación de abatir la sub-representación femenina en los cargos públicos de elección popular, lo que aborda el problema de manera superficial o sintomática, en lugar de hacerlo desde sus causas. Esa intención de combatir los problemas desde la superficie está basada en las posturas utilitaristas que pregonan su corrección con base en el impacto final y no desde la perspectiva de las causas; sin embargo, el utilitarismo durante muchos años ha sido una postura doctrinal que ha favorecido a la sociedad del bienestar pero que últimamente ha constituido un obstáculo para el progreso moral (Hampshire, 1983: 24). En contraposición con esto, Dworkin (1989: 17) sostiene que los objetivos sociales sólo son legítimos si respetan los derechos de los individuos, ya que una verdadera teoría de los derechos debe dar prioridad a los derechos frente a los objetivos sociales. Permitir la paridad de género es permitir que el concepto de ciudadano se vea fragmentado y que el voto sea clasificado con base en esos fragmentos, es decir, por género, y entonces ya no habría razón alguna para evitar que el voto de la ciudadanía se divida en voto masculino y en voto femenino. Si el argumento para la paridad es que el sector femenino de la ciudadanía se vea representado, entonces sería injusto no permitir o no considerar que el sector masculino se viera también representado, por lo que el discurso justo o la razón legal justa debería ser esa: se impone la paridad de género en virtud de que la ciudadanía (formada por hombres y mujeres) debe verse representada de forma proporcional de acuerdo a la realidad social. Con base en este último argumento se debería considerar el porcentaje de hombres y mujeres que hay en un determinado distrito o demarcación electoral para que en esa misma proporción se conformen los órganos y cargos públicos de elección popular, con lo que la paridad se estaría sustituyendo (por injusta) por una cuota realista y proporcional (más justa) respecto a las cantidades de género que existen en la realidad social. Lo mismo tendría que hacerse en cada distrito o demarcación territorial, dependiendo de la elección que se estuviera llevando a cabo:

“Al principio de libertad igual, cuando se aplica al proceso político definido por la constitución, lo llamaré 'principio de (igual) participación'. Este principio exige que todos los ciudadanos tengan un mismo derecho a tomar parte y a determinar el resultado del proceso constitucional que establecen las leyes que 
ellos han de obedecer. La justicia como imparcialidad comienza con la idea de que, si los principios generales son necesarios y ventajosos para todos, han de ser elaborados desde el punto de vista de una situación inicial de igualdad bien definida, donde cada persona está justamente representada" (Rawls, 2004: 210).

El objeto de la paridad de género debe ser la igualdad democrática, por tanto, los medios que emplee no deben afectarla ni alentar el desprecio ni la vulneración de las categorías que la componen. La paridad de género solamente podría justificarse si proporcionara justicia social y electoral que conserve las condiciones sociales necesarias para una justa igualdad de oportunidades electorales y no de sus resultados, debe ser una formulación que trate a todos los ciudadanos por igual y que no apoye su participación en los beneficios y cargas de los procesos electorales de acuerdo con su condición de género, la cual depende de condiciones biológicas aleatorias, tal como lo postula la igualdad democrática.

\section{Conclusión}

La paridad significa favorecer a priori al sector femenino sin considerar otros criterios cualitativos, con la justificación de abatir el problema de la sub-representación femenina en los cargos públicos de elección popular, sin embargo, solamente lo aborda de manera superficial o sintomática con base en el impacto final y no desde sus causas. En efecto, el ciudadano tiene una doble posibilidad democrático-electoral: acceder al proceso para competir por un cargo de elección y ganar en tal proceso para tomar posesión del mismo y ejercerlo; sin embargo, esa posibilidad no debe implicar la seguridad de que se gane el cargo, ya que se estaría imponiendo un resultado a priori incongruente con la igualdad democrática. Con la paridad de género se obliga a la participación electoral y también a su resultado, lo cual atenta contra esa libertad democrática que implica poder optar o no por una decisión de entre una serie de opciones; el efecto es una determinación apriorística del resultado electoral derivado de una decisión impuesta no razonada que atenta contra la decisión de participar misma que debe ser libre y democrática. Por otro lado, la igualdad de consideración y respeto es premisa en el tratamiento de la justicia desde la perspectiva de equidad de género: la misma consideración y el mismo respeto para hombres y mujeres, significa que las acciones que son resultado de las interacciones entre ellos deben tener su fundamento en una misma cantidad de atención que implica otorgarle una misma cantidad de importancia tanto a uno como a otro de los géneros. El concepto de "mismas oportunidades" significa que, bajo la igualdad democrática, hombres y mujeres deben tener los mismos momentos y las mismas circunstancias convenientes para el logro de las metas democráticas, es decir, la postulación y eventual ocupación y ejercicio de cargos públicos de elección popular. Considerando que la finalidad de un Estado democrático es la satisfacción de las necesidades de su pueblo y tomando en cuenta que hay mayores probabilidades de que eso lo obtenga alguien con capacidades y méritos adecuados, entonces los candidatos electos deben ser los que posean tales características. Por ello, el mérito es un criterio incompatible con las cuotas y con la paridad, ya que una posición inicial e ideal del ciudadano no es probable por ser una situación puramente hipotética y sus intereses pueden causar una trayectoria cuya meta no sea la ocupación de un cargo público de elección popular.

\section{Bibliografía}

Aguiar, Fernando, A favor de las cuotas femeninas, revista Claves de Razón Práctica, no. 116, España, 2001. 
Antón, Antonio, La desigualdad social, Universidad Autónoma de Madrid, España, 2013, en línea: https://www.uam.es/personal_pdi/economicas/aanton/publicacion/2014/desigualdad_social.htm.

Calsamiglia, Albert, Ensayo sobre Dworkin, en: Dworkin, Ronald, "Los derechos en serio", editorial Ariel, Barcelona, 1989.

Cano, Gabriela, Revolución, Feminismo y Ciudadanía en México 1915-1940, en "Historia de las Mujeres", vol. 5, "El siglo veinte", Georges Duby y Michelle Perrot, (coords.), editorial Taurus Minor, 2001, España.

Constitución Política de los Estados Unidos Mexicanos (CPEUM), Querétaro, México, 5 de febrero de 1917.

Diario Oficial de la Federación, Órgano del Gobierno Constitucional de los Estados Unidos Mexicanos, tomo DCCXXV, no. 6, México, D.F., lunes 10 de febrero de 2014.

Diario Oficial de la Federación, Órgano del Gobierno Constitucional de los Estados Unidos Mexicanos, tomo DLXXV, no. 10, México, D.F., martes 14 de agosto de 2001.

Diario Oficial de la Federación. Órgano del Gobierno Constitucional de los Estados Unidos Mexicanos, tomo DCLII, no. 9, México D. F., lunes 14 de enero de 2008.

Diario Oficial de la Federación. Órgano del Gobierno Constitucional de los Estados Unidos Mexicanos, tomo DCCXXVIII, no. 18, México, D. F., viernes 23 de mayo de 2014.

Diario Oficial. Órgano del Gobierno Constitucional de los Estados Unidos Mexicanos, tomo CC, no. 30, México, D.F., viernes 17 de octubre de 1953.

Diario Oficial. Órgano del Gobierno Constitucional de los Estados Unidos Mexicanos, tomo CLX, no. 35, México, miércoles 12 de febrero de 1947.

Diario Oficial. Órgano del Gobierno Constitucional de los Estados Unidos Mexicanos, tomo CCCXXVI, número 41, México, martes 31 de diciembre de 1974.

Dworkin, Ronald, El imperio de la justicia, Gedisa, Barcelona, España, 2012.

Dworkin, Ronald, Justicia para erizos, Fondo de Cultura Económica, México, 2014.

Dworkin, Ronald, Los derechos en serio, editorial Ariel, Barcelona, 1989.

El País, El Tribunal de la UE rechaza que la mujer tenga preferencia para la función pública. Declarada ilegal la ley sueca que permite el acceso femenino con menos cualificación, Bruselas, 7 de julio de 2000, en línea: http://elpais.com/diario/2000/07/07/sociedad/962920810_850215.html.

El País, Resoluciones judiciales de ida y vuelta, Madrid, 7 de julio de 2000, en línea http://elpais. com/diario/2000/07/07/sociedad/962920811_850215.html.

Hampshire, Stuart, Moral pública y privada, México, Fondo de Cultura Económica, 1983.

Medina Espino, Adriana, La participación política de las mujeres. De las cuotas de género a la paridad, Centro de Estudios para el Adelanto de las Mujeres y la Equidad de Género (CEAMEG), LXI Legislatura, Cámara de Diputados, México D. F. 2010, en línea: http://www. diputados.gob.mx/documentos/Comite_CEAMEG/Libro_Part_Pol.pdf.

Organización de las Naciones Unidas (ONU), Convención sobre los Derechos Políticos de la Mujer, plenario general no. 409, 20 de diciembre de 1952, en línea: http://www.acnur.org/ fileadmin/scripts/doc.php?file-fileadmin/Documentos/BDL/2001/0019, consultado el 10 de agosto de 2017.

Organización de las Naciones Unidas (ONU), Declaración Universal de los Derechos Humanos, Resolución 217 A (III), 10 de diciembre de 1948, París, Francia, en línea: http://www.un.org/ es/documents/udhr/UDHR_booklet_SP_web.pdf, consultado el 10 de agosto de 2017.

Organización de las Naciones Unidas (ONU), Derechos Humanos, Oficina del alto comisionado, Pacto Internacional de los Derechos civiles y políticos, Asamblea General, resolución 2200 A (XXI), 16 de diciembre de 1966, en línea: http://www.ohchr.org/SP/ProfessionaInterest/Pages/CCPR.aspx consultado el día 10 de agosto de 2017.

Pascoe Pierce, Ricardo, ¿Importa la manipulación de estadísticas?, Excelsior, 18 de julio de 2016, en línea: http://www.excelsior.com.mx/opinion/ricardo-pascoe-pierce/2016/07/18/1105581, fecha de consulta: 06 de agosto de 2017.

Plan Nacional de Desarrollo 2014-2018, en línea: http://www.dof.gob.mx/nota_detalle_popup. php?codigo-5299465, consultado el 10 de agosto de 2017. 
Rawls, John, Teoría de la justicia, Fondo de Cultura Económica, México, 2004.

Real Academia Española (RAE), Diccionario de la Lengua Española. Edición del Tricentenario, en línea: http://www.rae.es.

Salazar, Luis y Woldenberg, José, Principios y valores de la democracia, Instituto Federal Electoral, México D. F., 2012.

Virgen, Lucy, 17 de octubre de 1953 derecho al voto para la mujer en México, Universidad de Guadalajara, en línea: http://www.udg.mx/es/efemerides/17-octubre-0, 2011, consultada el 9 de agosto de 2017.

\section{3}

